\title{
EVIDÊNCIA DE VIDA GREGÁRIA EM PALEOTOCAS ATRIBUÍDAS A MYLODONTIDAE (PREGUIÇAS-GIGANTES)
}

\author{
FRANCISCO SEKIGUCHI BUCHMANN \\ Laboratório de Estratigrafia e Paleontologia, UNESP, São Vicente, SP, Brasil. \\ paleonchico@yahoo.com.br \\ HEINRICH THEODOR FRANK \\ Museu de Mineralogia "Luiz Englert", Instituto de Geociências, UFRGS, Porto Alegre, RS, Brasil. \\ paleotocas@gmail.com \\ VITOR MOREIRA SANDIM FERREIRA \\ Sul Americana de Metais, SAM, Salinas, MG, Brasil.vitor.sandin@hotmail.com \\ ERICK ANTAL CRUZ \\ Programa de Pós-Graduação em Geociências, UFRGS, Porto Alegre, RS, Brasil.erickantal@gmail.com
}

\begin{abstract}
EVIDENCE OF GREGARIOUS BEHAVIOUR IN PALEOBURROWS OF MYLONDONTIDAE (GIANT SLOTHS). This article presents evidence of gregarious behavior in paleoburrows attributed to giant sloths. Paleoburrows are biogenic structures in the shape of galleries and halls excavated by extinct giant mammals that lived in the Pliocene and Pleistocene. In the case discussed here, they were excavated in rocks composed by neoproterozoic metadiamictites with hematite of the Macaúbas Group (Nova Aurora Formation). The rocks, of glacial origin, underwent metamorphism, were strongly cemented by hematite and exhibit high hardness. In the north of Minas Gerais, were identified new paleoburrows distributed in a grouped manner, located in valleys with steep slopes embedded in geological faults. In each group, the paleoburrows are arranged on both sides of the valley, facing at each other. At the walls and roofs of the paleoburrows, there are hundreds of claw marks, forming parallel double marks and intertwined marks. Silicone molds of the marks were compared with hand bones of Valgipes sp. (Mylodontidae) deposited in the collection of PUC-MG; the size and morphology of the double marks allowed to attribute these paleoburrows to digging mylodontids (two-toed giant sloths). At the lateral walls of the paleoburrows we identified several polished surfaces of elliptical shape, each one with a diameter of approximately $2.4 \mathrm{~m}$. These polished surfaces aroused due to the abrasive action of the giant sloths' fur at their resting place. A single paleoburrow may show from 1 to 3 of these elliptical surfaces, suggesting a gregarious behavior of the sloths, who slept together in these spaces.
\end{abstract}

Key words: megafauna, Quaternary, Minas Gerais, ichnofossils.

RESUMO - Este estudo apresenta evidências de vida gregária em paleotocas atribuídas às preguiças-gigantes. As paleotocas são estruturas biogênicas na forma de galerias e salões escavados por mamíferos gigantes extintos que viveram no Plioceno e Pleistoceno. Foram escavadas em rochas compostas por metadiamictitos hematíticos neoproterozoicos do Grupo Macaúbas (Formação Nova Aurora). As rochas de origem glacial sofreram metamorfismo, são fortemente cimentadas por hematita, e apresentam elevada dureza. No norte de Minas Gerais foram identificadas novas paleotocas distribuídas de forma agrupada, em vales de encostas íngremes encaixados em falhas. Em cada agrupamento as paleotocas estão dispostas nos dois lados dos vales, umas em frente às outras. Nas paredes e no teto das paleotocas há centenas de marcas de garras, formando marcas duplas paralelas e marcas entrelaçadas. Moldes em silicone das marcas foram comparados com ossos das mãos de Valgipes sp. (Mylodontidae) depositados na coleção da PUC-MG; o tamanho e morfologia das marcas duplas permitem atribuir estas paleotocas a milodontídeos cavadores (preguiças-gigantes de dois dedos). Nas paleotocas foram identificadas diversas superfícies polidas de formato elíptico, com cerca de 2,4 $\mathrm{m}$ de diâmetro, atribuídas ao desgaste da rocha devido ao atrito da pelagem das preguiças-gigantes em seu local de repouso. Em uma mesma paleotoca podem ter 1 a 3 superfícies polidas elípticas, sugerindo que as preguiças-gigantes tinham hábito gregário, dormindo juntas.

Palavras-chave: megafauna, Quaternário, Minas Gerais, icnofósseis. 


\section{INTRODUÇÃO}

As paleotocas são estruturas biogênicas escavadas por mamíferos gigantes extintos que viveram no Plioceno e Pleistoceno. São estruturas de bioerosão e ocorrem na forma de galerias desobstruídas, possibilitando acesso ao seu interior. Foram primeiramente descritas na América do Sul em afloramentos do litoral argentino entre as cidades de Mar del Plata e Miramar (Província de Buenos Aires), em sedimentos areno-lamosos de coloração castanha amarelado a castanho avermelhado, de idade Plio-Pleistoceno com cerca de $3 \mathrm{Ma}$ (Ameghino, 1908; Frenguelli, 1921, 1928; Kraglievich, 1952; Vizcaíno et al., 2001; Dondas et al., 2009). No Uruguai, as paleotocas foram descritas por Ogando et al. $(2010,2011)$.

No Brasil, as paleotocas foram registradas no Rio Grande do Sul, Santa Catarina, Paraná, São Paulo, Rio de Janeiro e Minas Gerais (Bergqvist \& Maciel, 1994; Buchmann et al., 2009, 2015; Frank et al., 2011, 2012a,b, 2013, 2015; Carmo et al., 2011a,b). As paleotocas se enquadram na classificação de cavidades naturais subterrâneas. São consideradas estruturas de moradia temporária ou permanente e podem ser incluídas na classe etológica Domichnia (Seilacher, 1953; Frey, 1975; Bromley, 1990; Carvalho \& Fernandes, 2000).

A idade das paleotocas não pode ser determinada com precisão, pois a idade da rocha escavada não representa a idade da paleotoca. Na Argentina, as idades estão em torno de $3 \mathrm{Ma}$
(Plioceno); e no Brasil, em torno de $400 \mathrm{Ka}$ (Pleistoceno), não se descartando a possibilidade de idades próximas a $10 \mathrm{Ka}$ (Buchmann et al., 2009).

Frank et al. (2011) classificam as paleotocas de acordo com seu grau de preservação em cinco tipos: (i) paleotocas integralmente preservadas, sem preenchimento e cuja seção é elíptica ou circular, sem apresentar feições de colapso de teto, nem de erosão do piso; (ii) paleotocas que sofreram a erosão por águas correntes; (iii) paleotocas parcialmente preenchidas por sedimentos; (iv) paleotocas integralmente preenchidas por sedimentos, denominadas de crotovinas; (v) as dolinas e trincheiras, que são paleotocas cujo teto sofreu desabamento. Buchmann et al. (2009, 2015) e Frank et al. (2011) descrevem levantamentos topográficos, e revelam galerias com dezenas a centenas de metros de comprimento, atingindo até $340 \mathrm{~m}$ de comprimento, como a paleotoca identificada na Serra do Gandarela, em Minas Gerais (Ruchkys et al., 2014, 2015).

A ausência de restos fósseis no interior das galerias impede a identificação precisa do organismo responsável por sua escavação. As dimensões das galerias, as marcas de escavação e marcas de osteodermos presentes ao longo das galerias sugerem pelo menos dois escavadores: (i) mamíferos xenartros dasipodídeos (tatu-gigante) nas galerias com diâmetro entre 0,7 e 1,4 m; e (ii) mamíferos xenartros milodontídeos (preguiça-gigante) nas galerias com diâmetro de mais de $4 \mathrm{~m}$ (Figura 1). Frank et al. $(2011,2015)$ registram

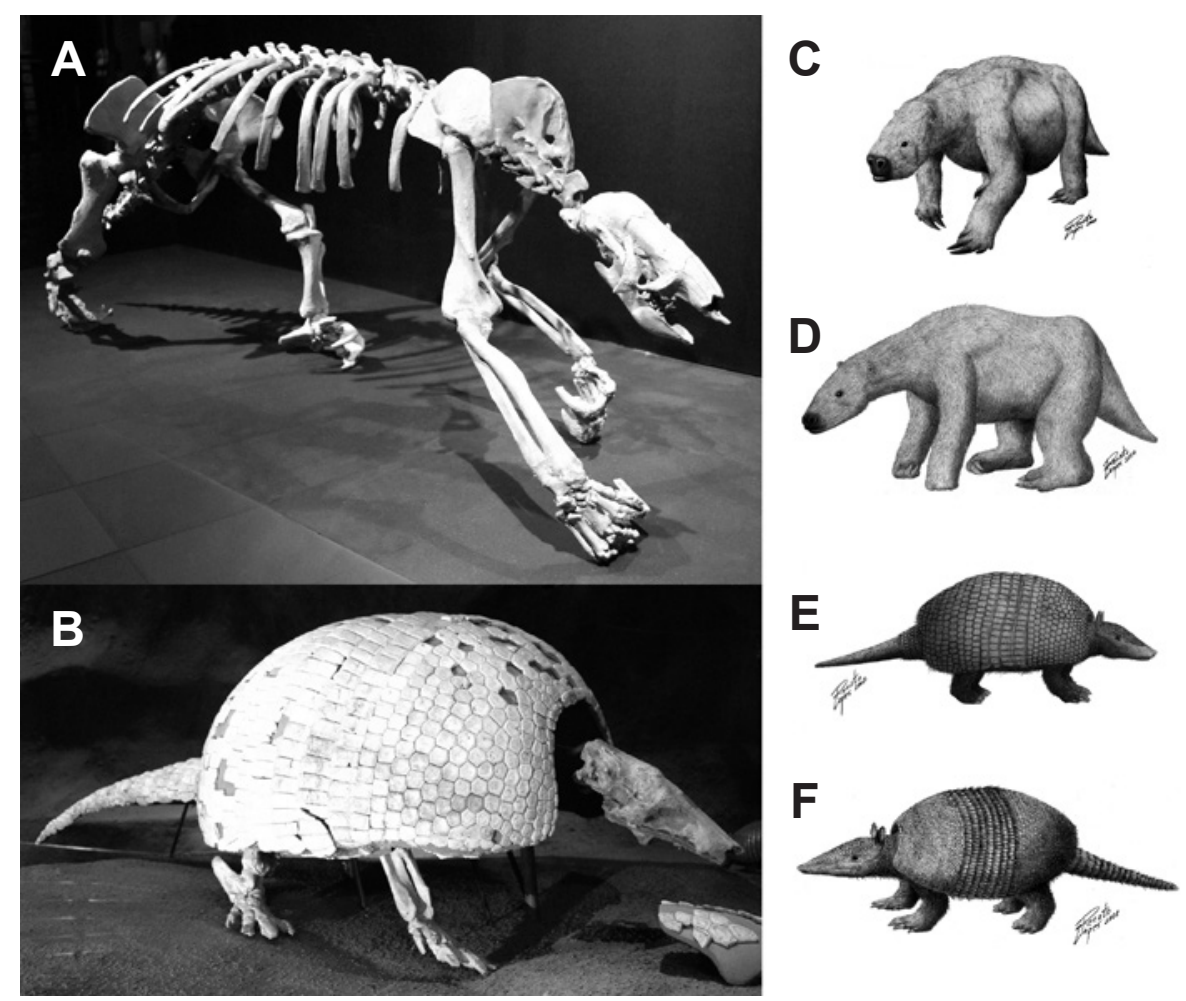

Figura 1. Táxons provavelmente envolvidos na produção de paleotocas: A, Nothrotherium (preguiça-gigante); B, Pampatherium (tatu-gigante); C, Glossotherium robustum; D, Catonyx cuvieri; E, Pampatherium humboldtii; F. Propraopus grandis. A-B, fotos por Francisco Buchmann; C-F, Desenhos de Renato Lopes. Sem escala.

Figure 1. Taxa probably involved in the production of paleoburrows: A, Nothrotherium (giant sloth); B, Pampatherium (giant armadillo); C, Glossotherium robustum; D, Catonyx cuvieri; E, Pampatherium humboldtii; F, Propraopus grandis. A-B, photo by Francisco Buchmann; C-F, drawings of Renato Lopes. Not scale. 
no Rio Grande do Sul paleotocas atribuídas a preguiças gigantes compostas por grandes salões, com larguras de até $4 \mathrm{~m}$, alturas de até $2 \mathrm{~m}$ e comprimento de até $40 \mathrm{~m}$. Carmo et al. (2011a,b), Ruchkys et al. $(2014,2015)$ e Buchmann et al. (2015) descrevem em Minas Gerais paleotocas semelhantes, com alturas de $4 \mathrm{~m}$, largura de $10 \mathrm{~m}$ e comprimento de $40 \mathrm{~m}$.

Entre os tatus-gigantes têm-se o Pampatherium sp. e Holmesina sp. (Pampatheriinae), Eutatus sp. e Propraopus sp. (Dasypodidae); e entre as preguiças-gigantes cavadoras (Mylodontidae) têm-se Valgipes sp. e Scelidotherium sp. que habitavam o cerrado brasileiro e o pampa argentino, respectivamente (Zárate \& Fasano, 1989; Quintana, 1992; Zárate et al., 1998; Vizcaíno et al., 2001; Cartelle et al., 2009; Lopes \& Pereira, 2010).

A megafauna de mamíferos representada pelos seus fósseis e icnofósseis (paleotocas) foi extinta no final do Pleistoceno, e pode ser encontrada em diversas fácies sedimentares em toda a América do Sul. A xenartria pode estar associada a uma especialização do esqueleto pós-craniano para o hábito de escavar, e permitiu que tatus suportassem a pesada carapaça, e as preguiças terrícolas sustentassem o peso do corpo em posição vertical. A postura bípede é importante durante a escavação, porque os membros anteriores devem escavar o substrato (Bargo et al., 2000). Segundo Fariña \& Vizcaíno (1997) e Vizcaíno et al. $(1999,2003)$ os membros anteriores são mais especializados para o hábito fossorial, enquanto que os membros posteriores são mais especializados para a sustentação do peso.

Os icnofósseis, como as paleotocas, são especialmente propícios para revelar hábitos de vida de organismos fossoriais. Normalmente as paleotocas apresentam em suas paredes e teto diversas marcas de arrasto da carapaça e/ ou marcas de garras dos membros durante a escavação. O presente estudo pretende descrever as paleotocas no norte de Minas Gerais, identificar os organismos fossoriais e discutir seus hábitos de vida gregários.

\section{GEOLOGIA}

A área de estudo está inserida no geossistema cangas/ formações ferríferas associado ao Membro Riacho Poções (Formação Nova Aurora). O Membro Riacho Poções é representado por pacote de metadiamictito hematítico, com espessura de até $90 \mathrm{~m}$, e intercalações localizadas de metadiamictito magnetítico cinza com até $10 \mathrm{~m}$ de espessura. Essa unidade constitui-se predominantemente por metadiamictitos hematíticos, quartzitos hematíticos e xistos hematíticos subordinados (Vilela, 1986). Segundo Vilela et al. (1978), os metadiamictitos hematíticos, que constituem o minério de ferro, apresentam bandeamento e são formados por leitos de quartzo contendo cristais de hematita, que se alternam com leitos de hematita associada à sericita e clorita. Grande parte de toda essa sequência de litotipos hematíticos está sob uma extensa cobertura de canga, que frequentemente atinge cerca de $30 \mathrm{~m}$ de espessura. Superficialmente, as cangas apresentam fragmentos detríticos de minério rico e são compostas geralmente por limonita pura (Vilela, 1986).
As altitudes dos platôs de canga variam entre 850 e 950 m, ocorrendo um desnível de até $80 \mathrm{~m}$ em relação às superfícies terciárias contíguas.

No Neoproterozoico, por volta de $900 \mathrm{Ma}$, o continente São Francisco-Congo começa a se fragmentar (Vilela, 2010). Segundo Pedrosa-Soares et al. (2007) ocorreu a Tafrogênese Toniana, acompanhada de magmatismo e sedimentação glaciogênica, sendo esta responsável pela formação da Bacia Macaúbas. Na fase rifte da Bacia Macaúbas depositaramse as rochas das formações Matão, Duas Barras, Rio Peixe Bravo, pré-glaciais, Serra do Catuni, Nova Aurora e a parte inferior da Formação Chapada Acauã, glaciogênicas (Pedrosa-Soares et al., 1992; Noce et al., 1997; Uhlein et al., 1998; Martins et al., 2008). Esse rifte evolui para margem passiva e assoalho oceânico.

Os metadiamictitos do Grupo Macaúbas representam depósitos subaquosos que foram muito deformados e metamorfizados (Noce et al., 1997; Uhlein et al., 2007; Pedrosa-Soares et al., 2007). Estes autores identificaram entre os municípios de Salinas e Porteirinha, no norte de Minas Gerais as formações Rio Peixe Bravo (filitos e quartzitos) e Nova Aurora (diamictitos ferruginosos ou não, filitos, quartzitos hematitos bandados). A Formação Nova Aurora apresenta deposição cíclica de sedimentos grossos a finos, acamamento gradado, contatos erosivos entre ciclos e estruturas de carga, sendo caracterizada pelo enriquecimento em hematita, encerrando enormes depósitos (Noce et al., 1997). Morfologicamente, trata-se de uma área de extensas chapadas dissecadas por meio de um novo ciclo de denudação (Vilela, 1986; Viveiros et al., 1979).

\section{MATERIAL E MÉTODOS}

\section{Atividade de campo}

O trabalho de campo foi realizado em duas etapas. As paleotocas foram identificadas na primeira etapa entre 23 a 30 de janeiro de 2012. A segunda etapa, entre 04 e 16 de fevereiro de 2013, abordou o estudo detalhado das paleotocas. O mapeamento e a topografia das paleotocas com precisão BCRA 4C foram elaboradas pela Brandt Meio Ambiente. O procedimento de pesquisa nas paleotocas seguiu Buchmann et al. (2009). O georreferenciamento das paleotocas utilizou um GPS marca Garmin modelo Etrex Legend $H$. As cavidades apresentam um perfil irregular, assim, é admitido que os primeiros metros (vertical) a contar do chão, representam a parede, enquanto que a parte superior (horizontal) representa o teto. A quantidade de marcas de garras ao longo de cada paleotoca foi estimada; medida a cada metro, com um quadrado de $1 \mathrm{~m}^{2}$ e uma trena de $5 \mathrm{~m}$, a densidade de marcas de garra por $\mathrm{m}^{2}$, altura das marcas ao longo da paleotoca e a quantidade estimada de marcas de garras por paleotoca.

Em três paleotocas (VG-05, VG-06 e Maracanã) foram feitos moldes em silicone das marcas. O estudo das dimensões internas da paleotoca (comprimento, largura, altura, rumo, elevação) e das marcas (número, densidade e distribuição) auxiliou na identificação do organismo gerador. 
Foram feitas fotografias com escala das entradas e dos salões, para avaliar o formato da galeria, e fotos de detalhe das marcas nas paredes com o objetivo de identificar o organismo responsável pela escavação. Utilizou-se uma máquina Nikon D60 com lente Sigma grande angular 12-24 mm F4.5-5.6 DG e uma Nikon D7000 com lente Nikon 18-105 mm 3.5-5.6 ED.

\section{Atividade de laboratório}

Após o trabalho de campo, os resultados foram analisados no Laboratório de Estratigrafia e Paleontologia da Universidade Estadual Paulista (UNESP), Campus do Litoral Paulista, São Vicente, SP. As atividades em laboratório envolveram a organização e digitalização de um banco de dados digital com as informações obtidas na atividade de campo (localização geográfica, medidas das galerias, moldes em silicone de suas marcas, e fotografias da morfologia interna das paleotocas).

A classificação das marcas nas fotografias e das marcas nos moldes em silicone foi feita através da comparação com as descrições nos trabalhos de Paula Couto $(1973,1980 \mathrm{a}, \mathrm{b}$, 1982), Edmund (1985a,b), Quintana (1992), Bergqvist \& Maciel (1994), Becker \& Dalponte (1999), Buchmann et al. (2009, 2015) e Frank et al. (2011). Os moldes em silicone das marcas foram comparados com ossos das mãos de Valgipes sp. (Mylodontidae) e Pampatherium sp. (Pampatheriidae) depositados na coleção do Museu da Pontifícia Universidade Católica de Minas Gerais (PUC-MG), sob responsabilidade do Dr. Cástor Cartelle.

\section{RESULTADOS}

No norte de Minas Gerais foram identificadas 15 novas paleotocas escavadas por integrantes da megafauna de mamíferos extintos. Os locais de acesso difícil e muito bem preservados se situam em vales de encostas íngremes encaixados em falhas. As paleotocas foram escavadas em rochas compostas por metadiamictitos hematíticos neoproterozoicos do Grupo Macaúbas (Formação Nova Aurora). Na Figura 2 observa-se o mapa com a localização das paleotocas. As coordenadas geográficas, dimensões e altimetria das paleotocas estão na Tabela 1 .

\section{Descrição dos agrupamentos de paleotocas}

As paleotocas escavadas pela megafauna de mamíferos extintos estão distribuídas na área de estudo em quatro agrupamentos, totalizando quinze paleotocas: um grupo de seis paleotocas no Rio Esmeril (paleotocas VG-02, VG-03, VG-04, VG-05, VG-06 e VG-07) denominado de "Vale dos Gigantes"; um grupo de sete paleotocas no Rio Jiboia

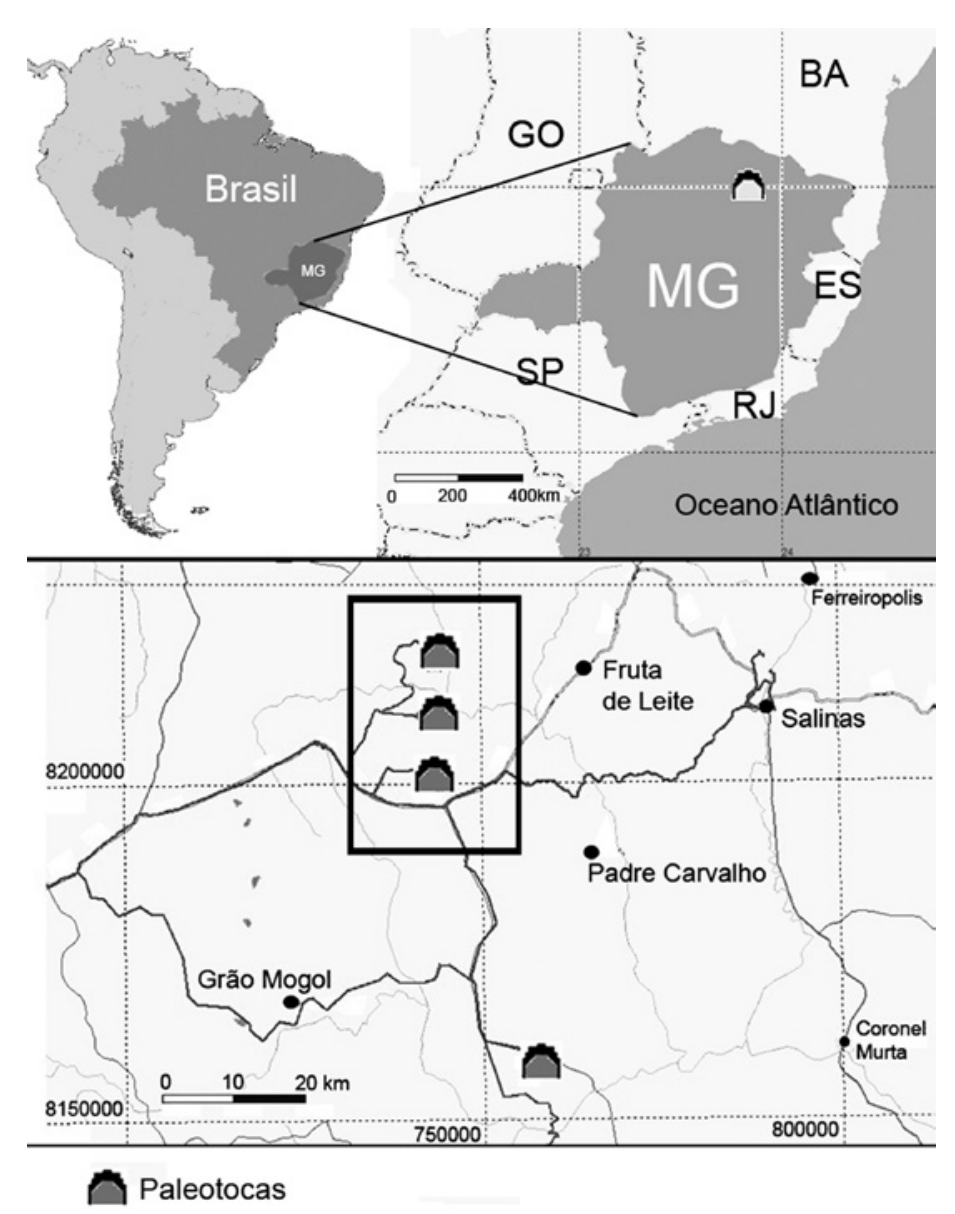

Figura 2. Mapa de localização dos quatro agrupamentos de paleotocas estudadas. Veja mais detalhes na Figura 3.

Figure 2. Location map of the four groups of studied paleoburrows. See more details in Figure 3. 
(paleotocas B-2, B-4, B-5, B-6, B-15, B-20 e B-21); uma paleotoca no córrego Lamarão (paleotoca $\mathrm{CM}-10$ ); e uma paleotoca no ribeirão Santana (paleotoca Maracanã). $\mathrm{Na}$ Figura 3 pode ser observada a distribuição agrupada das paleotocas. A distância entre os agrupamentos varia de 7 a $8 \mathrm{~km}$. Os agrupamentos são formados por cinco a sete paleotocas dispostas num raio de $250 \mathrm{~m}$.

\section{Descrição das paleotocas}

As paleotocas ocorrem em locais de acesso difícil e muito bem preservados, se situam em vales de encostas íngremes encaixados em uma falha. Geologicamente são compostas por metadiamictitos hematíticos neoproterozoicos do Grupo Macaúbas (Formação Nova Aurora). As rochas de origem glacial sofreram metamorfismo, são fortemente cimentadas por hematita, e apresentam elevada dureza.

Foi denominado "Vale dos Gigantes" o local onde seis paleotocas estão dispostas nos dois lados do vale do Rio Esmeril, umas em frente às outras (Figura 3); e formam salões com 50 a $270 \mathrm{~m}^{3}$, cujas entradas possuem $2 \mathrm{~m}$ de diâmetro. Internamente, os salões possuem 5 a $40 \mathrm{~m}$ de comprimento, $5 \mathrm{a}$ $10 \mathrm{~m}$ de largura, e 2 a $4 \mathrm{~m}$ de altura. As paleotocas apresentam luminosidade somente nos primeiros metros, sendo consideradas área de penumbra ou afóticas em seu interior. Os locais com acúmulo de sedimentos foram superficialmente investigados, mas não foram identificados ossos fósseis. As superfícies polidas por atrito de formato elíptico (interpretado como local de repouso) estão parcialmente preenchidas por camadas de 30 a $40 \mathrm{~cm}$ de sedimento fino (silte e argila) e apresentam alto potencial fossilífero.

\section{Descrição das marcas nas paredes das paleotocas}

Em todas as paleotocas foram identificadas nas paredes e teto diversas marcas de garras feitas durante a escavação. As paleotocas VG-02, VG-04, VG-07 e CM-10 apresentam poucas marcas ou marcas mal preservadas e as paleotocas Maracanã, VG-03, VG-05 e VG-06 apresentam muitas marcas bem preservadas. A comparação entre o número de marcas ao longo das paleotocas (Figura 4) permite observar um aumento das marcas em direção do fundo das paleotocas, na zona afótica. Isto foi devido ao abatimento do teto na entrada, na área fótica. Provavelmente toda a paleotoca estava coberta por marcas, mas o intemperismo e o abatimento na entrada destruíram parte do registro.

Marcas de garras duplas paralelas foram observadas, bem como marcas entrelaçadas, sugerindo o uso das falanges II e III. A comparação das fotos das marcas e dos moldes em silicone das marcas com os ossos das mãos de Valgipes sp. (Mylodontidae) e Pampatherium sp. (Pampatheriidae) depositados na coleção do Museu da PUC-MG, descarta Pampatheriidae, e sugere que um milodontídeo cavador (preguiça-gigante de dois dedos) foi responsável pela escavação e/ou ampliação da cavidade (Figura 5). Apoiando esta afirmativa têm-se as grandes dimensões das paleotocas (cerca de $10 \mathrm{~m}$ de largura e $3 \mathrm{~m}$ de altura).

Na paleotoca B-4 foi observada a convergência em "Y" das marcas duplas, indicando a aproximação das falanges durante o processo de escavação (Figura 6). Em quase todas as paleotocas identificou-se a ocorrência de uma a três superfícies polidas de formato elíptico em uma mesma paleotoca. Estas marcas foram atribuídas ao desgaste da rocha devido ao atrito com a pelagem das preguiças-gigantes em seu local de repouso (Figuras 7-8). As marcas são bem definidas, e foram feitas em metadiamictito, rocha muito dura e resistente, mostram que o local de repouso era permanente. As medidas dos locais de repouso variaram entre 1,5 a 3,4 m de comprimento, com média de $2,4 \mathrm{~m}$; e as larguras variaram entre 1,4 a 1,8 m, com média de 1,56 m, sendo compatíveis com as dimensões das preguiças gigantes.

Tabela 1. Localização das paleotocas.

Table 1. Location of the paleoburrows.

\begin{tabular}{ccccc}
\hline & UTM E & UTM N & Projeção (m) & Elevação (m) \\
\hline CM-10 & 23K 742071 & 8200970 & 36,55 & 852 \\
Maracanã & 23K 755934 & 8156029 & 26,50 & 709 \\
VG-02 & 23K 743744 & 8217248 & 9,90 & 740 \\
VG-03 & 23K 743717 & 8217285 & 33,30 & 756 \\
VG-04 & 23K 743661 & 8217252 & 9,10 & 741 \\
VG-05 & 23K 743732 & 8217240 & 18,30 & 740 \\
VG-06 & 23K 743709 & 8217204 & 22,90 & 749 \\
VG-07 & 23K 743860 & 8217133 & 12,80 & 731 \\
B -2 & 23K 742371 & 8209505 & 11,30 & 738 \\
B -4 & 23K 742081 & 8209820 & 16,10 & 738 \\
B -5 & 23K 742071 & 8209821 & 38,60 & 737 \\
B -6 & 23K 742133 & 8210286 & 6,05 & 778 \\
B - 15 & 23K 741769 & 8209758 & 6,20 & 736 \\
B -20 & 23K 741629 & 8209623 & 5,10 & 748 \\
B -21 & 23K 741627 & 8209515 & 9,30 & 752 \\
\hline
\end{tabular}




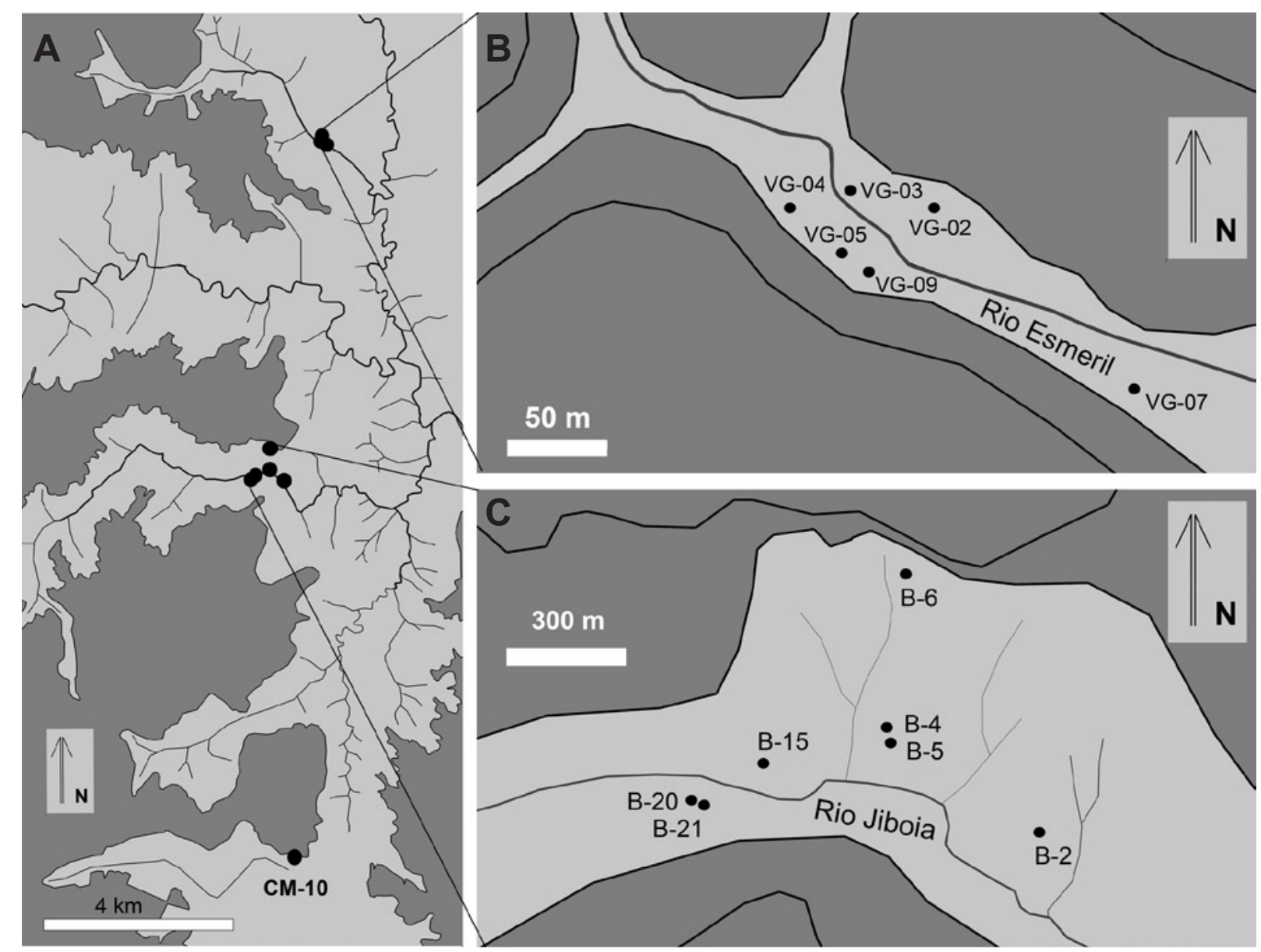

Figura 3. Mapa ampliado da área das paleotocas (A) com a distribuição das mesmas nos rios Esmeril (B) e Jiboia (C).

Figure 3. Enlarged map of the area of paleoburrows (A) with the distribution in Esmeril (B) and Jiboia (C) rivers.
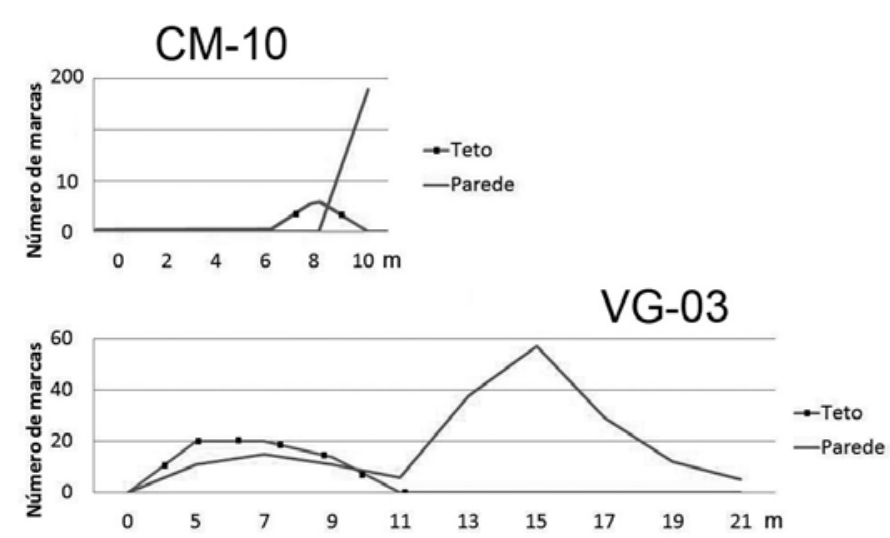

VG-07

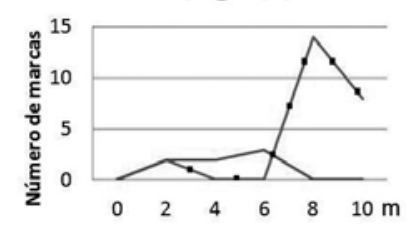

VG-02

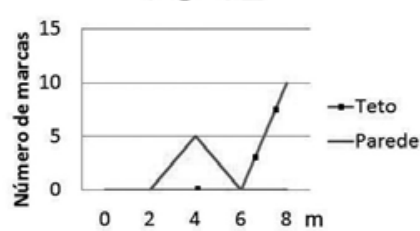

Maracanã

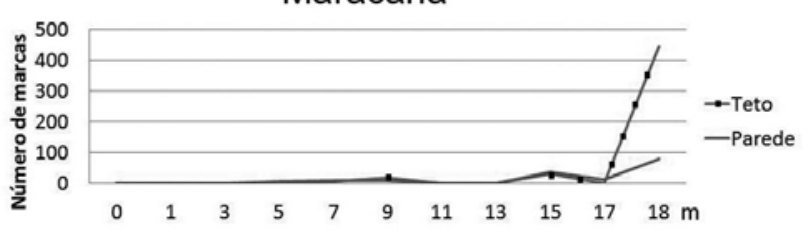

VG-05

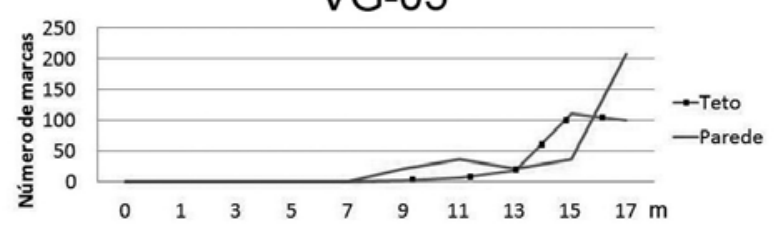

VG-06

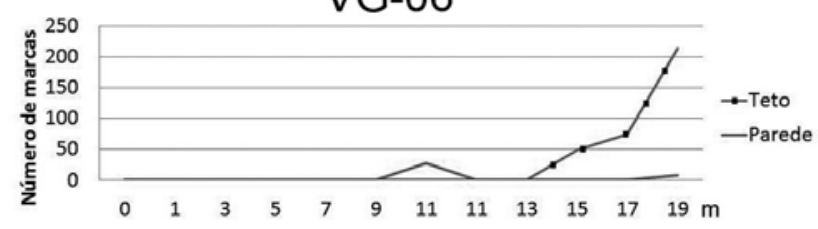

Figura 4. Comparação entre o número de marcas no teto e na parede das paleotocas.

Figure 4. Comparison between the number of marks in the ceiling and walls of the paleoburrows. 


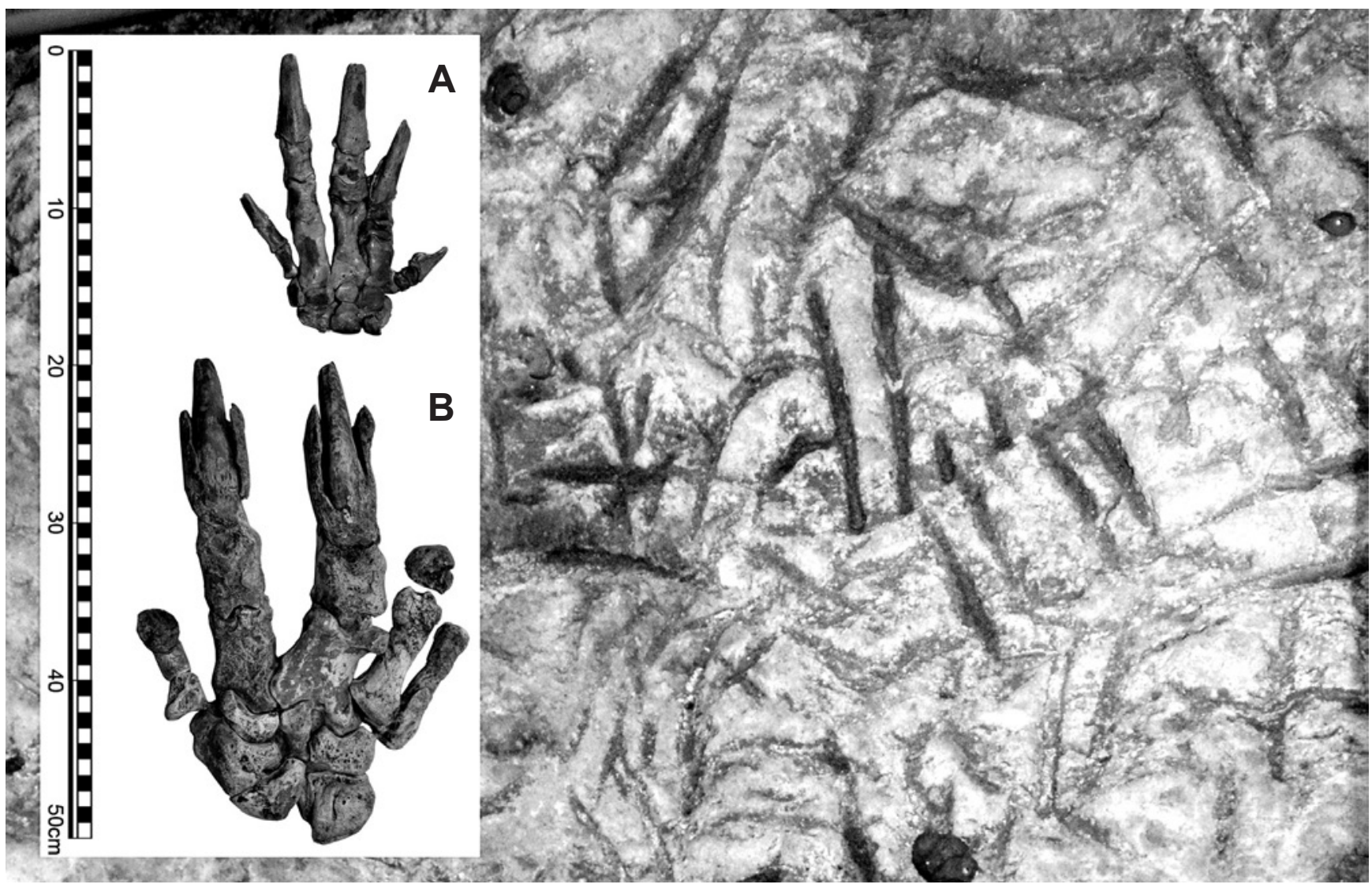

Figura 5. Comparação entre as marcas com os ossos das mãos de Pampatherium sp. (A) e Valgipes sp. (MCL 4293 de Cartelle et al., 2009 ) (B). Escala $=50 \mathrm{~cm}$.

Figure 5. Comparison between the marks and hand bones of Pampatherium sp. (A) and Valgipes sp. (MCL 4293 of Cartelle et al., 2009) (B). Scale bar $=50 \mathrm{~cm}$.
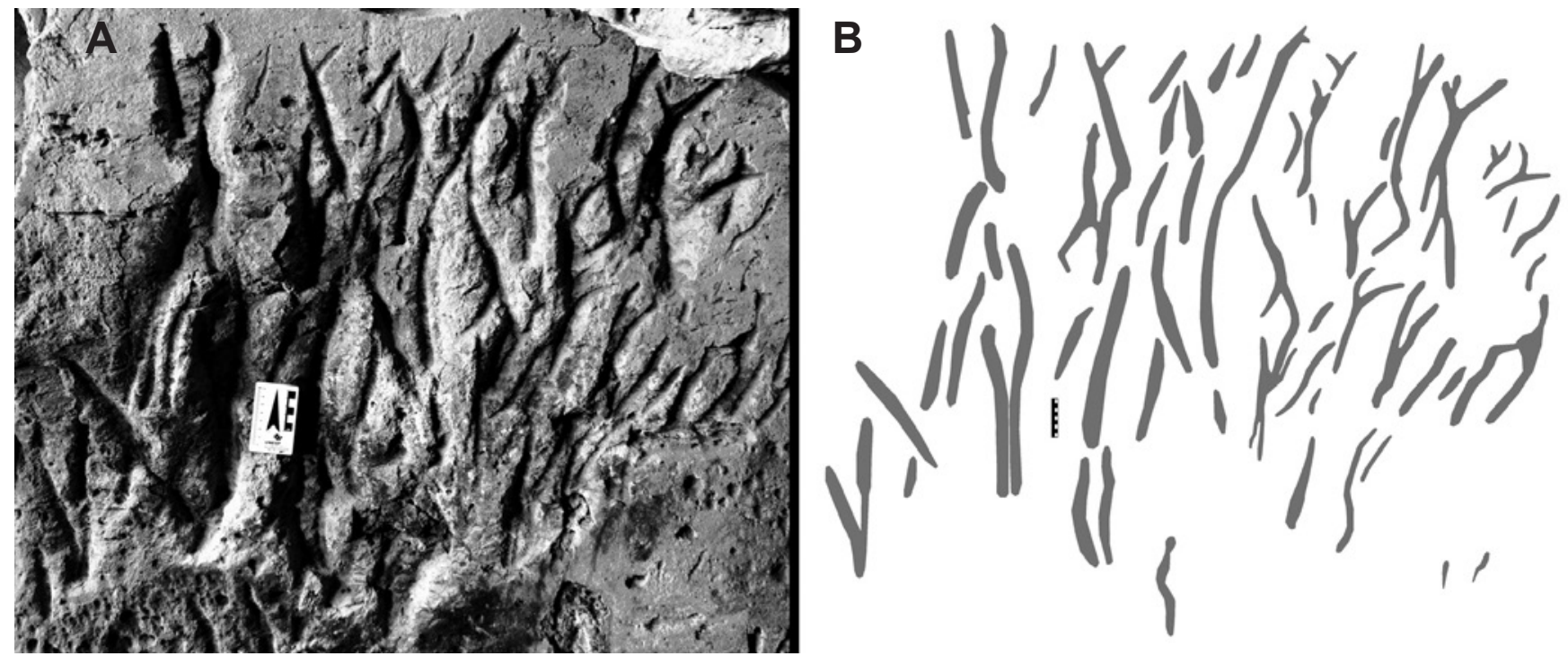

Figura 6. Fotografia (A) e desenho (B) das marcas de garras na cavidade B-4, onde se observa a convergência em "Y" nas marcas. Escalas $=5 \mathrm{~cm}$.

Figure 6. Photography $(\mathbf{A})$ and drawing $(\mathbf{B})$ of the claw marks in the cavity B-4, where observe the "Y" convergence in the marks. Scale bars $=5 \mathrm{~cm}$. 

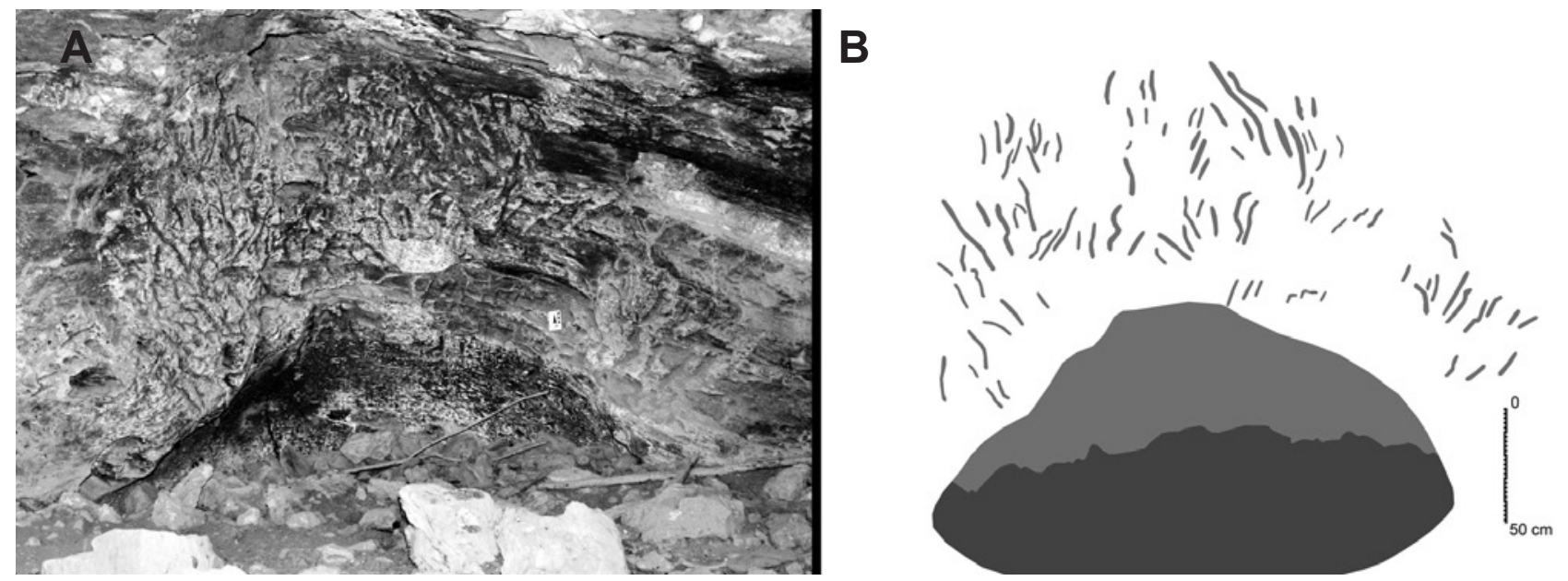

Figura 7. Fotografia (A) e desenho (B) das marcas de garras (acima) e da superfície polida de formato elíptico (abaixo) na cavidade B-4. Escala $=50 \mathrm{~cm}$.

Figure 7. Photography (A) and drawing (B) of the claw marks (upper) and the polished surfaces of elliptical shape (lower) in the cavity B-4. Scale bar $=50 \mathrm{~cm}$.
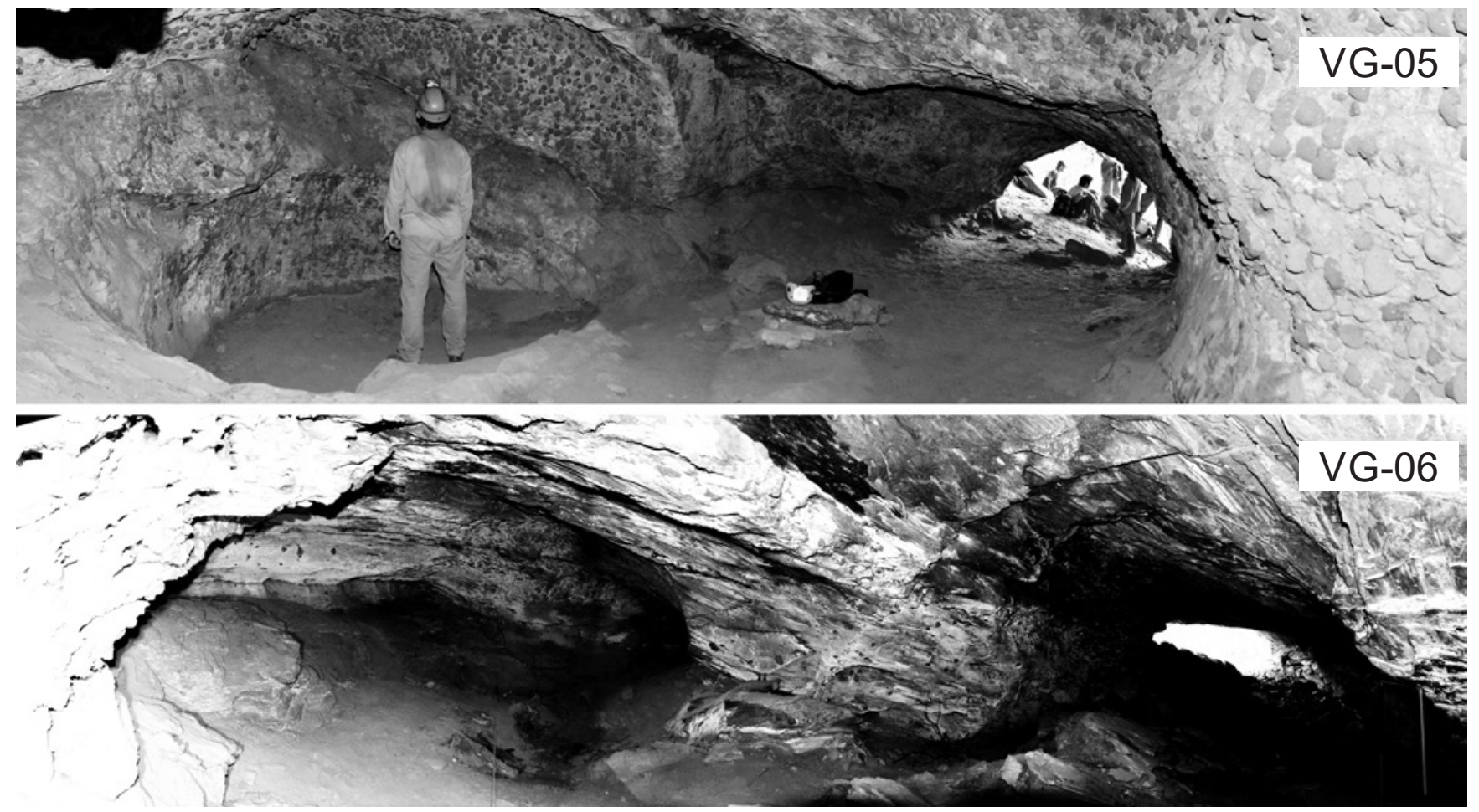

Figura 8. Superfície polida de formato elíptico atribuída ao desgaste da rocha devido ao atrito com a pelagem das preguiças-gigantes nas paleotocas VG-05 e VG-06.

Figure 8. Polished surfaces of elliptical shape attributed to the rock abrasion by the friction of the pelage of giant sloths in the paleoburrows VG-05 e VG-06.

\section{DISCUSSÃO}

A distribuição agrupada das paleotocas no rio Esmeril (Vale dos Gigantes) e no rio Jiboia indica que várias preguiças escolheram o mesmo local para construir suas tocas (Figura 3). Uma toca do lado da outra, de forma agrupada, e não de forma aleatória. Preguiças sozinhas ou em casal morando próximas umas às outras, foi interpretado como evidência de comportamento gregário e relação social. Naples (1990) sugere que Paramylodon pode ter formado grupos sociais e um estilo de vida polígamo. McDonald (2006) observa que as diferenças em tamanho e anatomia entre as atuais preguiças arborícolas e as preguiças terrestres extintas sugere que as formas extintas tinham um repertório social mais diversificado.

Atualmente existem seis espécies de preguiças, distribuídas em dois gêneros: Bradypus (preguiça-de-três-dedos) e 


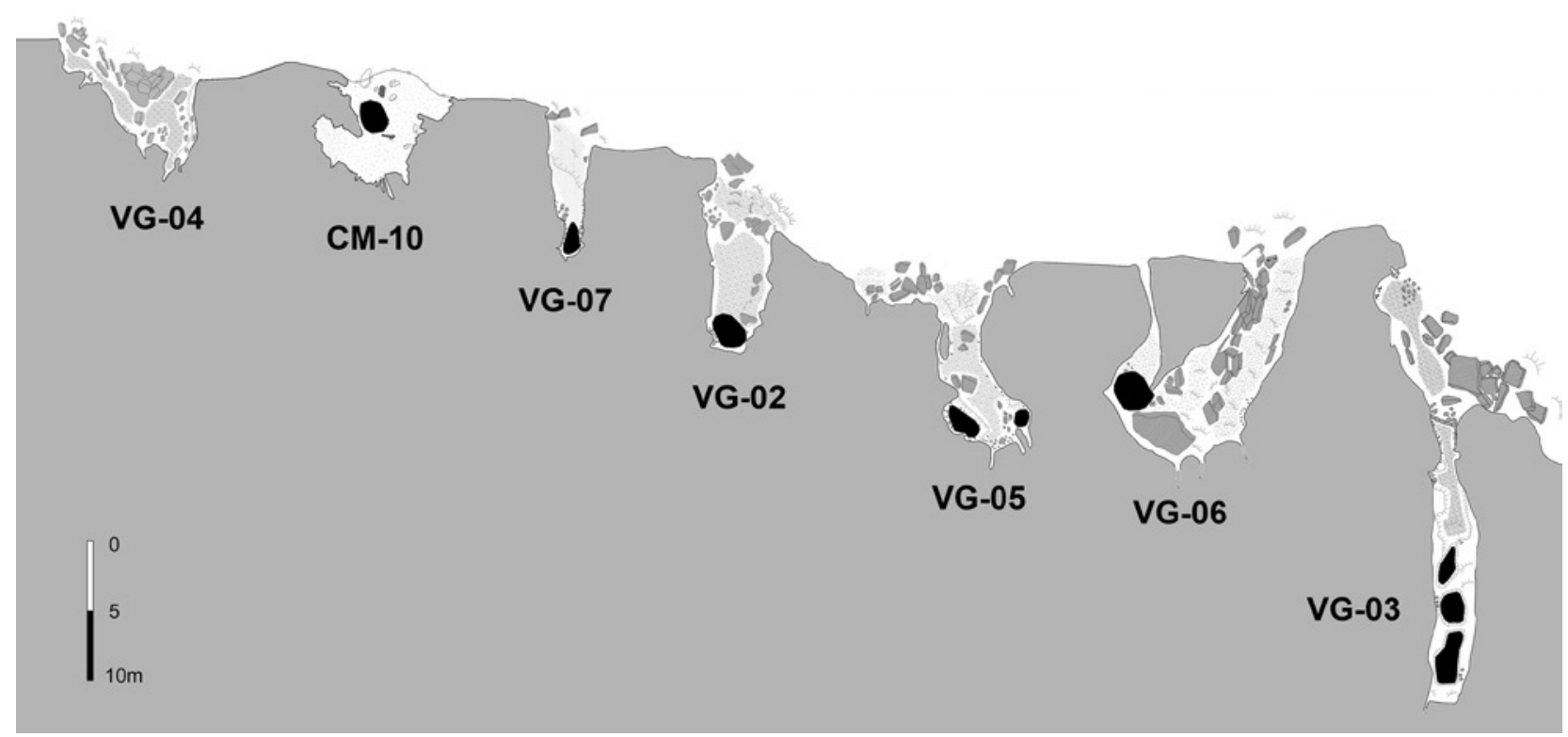

Figura 9. Comparação entre o formato da planta baixa das paleotocas, o círculo preto representa a superfície polida de formato elíptico interpretada como locais de repouso (modificado de Buchmann et al., 2015). Para a localização das paleotocas vide Figura 3.

Figure 9. Comparison between the shapes of the paleoburrows plan, the black circle represents the elliptical polished surface interpreted as rest places (modified from Buchmann et al., 2015). For location of paleoburrows see Figure 3.

Choloepus (preguiça-de-dois-dedos); elas são solitárias, estão adaptadas ao ambiente arborícola, e tem grande dificuldade de andar no chão. No passado existiam mais de 100 espécies extintas, classificadas em 35 gêneros; e tiveram ampla distribuição geográfica nas Américas, habitando ambientes distintos e com comportamentos distintos.

No Chile durante o Mio-Plioceno as preguiças terrícolas entravam no mar, com hábitos aquáticos. O gênero Thalassocnus possuía os membros anteriores mais compridos que os membros posteriores para se agarrar ao fundo e se alimentar de algas, adaptando-se ao ambiente marinho (McDonald \& De Muizon, 2002; De Muizon et al., 2004a,b). No Brasil e Argentina, durante o Plio-Pleistoceno, as preguiças tinham hábitos fossoriais e escavavam suas tocas na forma de grandes galerias e salões (Buchmann et al., 2009, 2015; Frank et al., 2011, 2015; Carmo et al., 2011a,b). McDonald (2006) argumenta que as atuais preguiças arborícolas não são boas analogias para estudar a fisiologia, comportamento ou morfologia das preguiças extintas. Portanto, não é possível comparar o comportamento de preguiças atuais (arborícolas) com o comportamento de preguiças extintas (terrícolas, natantes e fossoriais).

Frank et al. (2013) foram os primeiros a descrever superfícies polidas nas paleotocas no Rio Grande do Sul, destacando que não são o resultado da erosão, uma vez que são coincidentes com a secção elíptica das galerias. A erosão devido a águas pluviais teria apagado as marcas de garras na porção inferior das paredes, onde elas ainda estão presentes. Os autores interpretam que foram produzidas pelo contínuo esfregar dos pêlos das preguiças gigantes no teto e nas paredes laterais durante o uso. Este contato permanente apagou as marcas de garras e produziu as superfícies lisas nas porções superiores das galerias, mas preservando as marcas nas porções inferiores.

As superfícies polidas descritas nas paleotocas em Minas Gerais (neste trabalho) também foram atribuídas ao desgaste da rocha devido ao atrito com a pelagem das preguiças gigantes (Figuras 7-8). Entretanto, foi observado que as superfícies polidas têm formato elíptico, o que sugere que as preguiças gigantes tinham local de repouso bem definido. O tamanho médio $(2,4 \mathrm{~m})$ da superfície de forma elíptica seria proporcional ao tamanho do animal.

A comparação entre as plantas baixas permite observar que as paleotocas VG-04, CM-10, VG-07 e VG-02 representam o início da escavação, com pequeno volume, parcialmente iluminado e sem local de repouso bem definido; e as paleotocas VG-05, VG-06, VG-03 e Maracanã representam a conclusão da escavação, com grande volume, zona afótica, e dois ou três locais de repouso bem definidos (Figura 9), sugerindo que as preguiças-gigantes tinham hábito gregário, dormindo juntas.

Frank et al. $(2012 b, 2013)$ descrevem galerias semelhantes em Capão do Leão no Rio Grande do Sul, e em Timbé do Sul em Santa Catarina; Ruchkys et al. (2014) e Bittencourt et al. (2015) descrevem a paleotoca da Serra do Gandarela em Minas Gerais, que possui comprimento total de $340 \mathrm{~m}$, sendo a maior paleotoca conhecida, até o momento. Estes autores sugerem que a escavação foi gradual, realizada por gerações sucessivas de grupos de preguiças, e não por um animal individual. Apoiando esta afirmativa, se têm as grandes dimensões das paleotocas, onde cabem grupos de preguiças; e várias paleotocas uma do lado da outra, com distribuição agrupada, escavadas em rochas muito resistentes e difíceis de cavar. 


\section{CONCLUSÕES}

No norte de Minas Gerais, foram identificadas novas paleotocas distribuídas de forma agrupada, em vales de encostas íngremes encaixados em falhas. Em cada agrupamento as paleotocas estão dispostas nos dois lados dos vales, umas em frente às outras. Nas paredes e no teto das paleotocas há centenas de marcas de garras, formando marcas duplas paralelas. O tamanho e morfologia das marcas duplas permitem atribuir estas paleotocas a milodontídeos cavadores (preguiças-gigantes de dois dedos). Numa mesma paleotoca foram identificadas de 1 a 3 superfícies polidas de formato elíptico, atribuídas ao desgaste da rocha devido ao atrito com a pelagem das preguiças-gigantes em seu local de repouso, sugerindo que as preguiças-gigantes tinham hábito gregário, dormindo juntas.

\section{AGRADECIMENTOS}

Os autores agradecem a C. Cartelle por permitir a comparação entre os moldes de silicone das marcas com os esqueletos da megafauna da coleção da PUC-MG. Aos revisores pelas ótimas sugestões na elaboração do texto. Projeto parcialmente financiado pelo CNPq 401772/2010-1, com apoio da SAM Metais.

\section{REFERENCIAS}

Ameghino, F. 1908. Las formaciones sedimentarias de la región litoral de Mar del Plata y Chapadmalal. Museo de Historia Natural de Buenos Aires, 7:343-428.

Bargo, M.S.; Vizcaíno, S.F.; Archuby, F. \& Blanco, R.E. 2000. Limb bone proportions, strength and digging in some Lujanian (Late Pleistocene-Early Holocene) mylodontid ground sloths (Mammalia, Xenarthra). Journal of Vertebrate Paleontology, 20:601-610. doi:10.1671/0272-4634(2000)02006061:LBPSA D]2.0.CO;2

Becker, M. \& Dalponte, J.C. 1999. Rastros de mamíferos silvestres brasileiros. Brasília, Editora UnB, 180 p.

Bergqvist, L.P. \& Maciel, L. 1994. Icnofósseis de mamíferos (crotovinas) na planície costeira do Rio Grande do Sul. Anais da Academia Brasileira de Ciências, 66:189-197.

Bittencourt, J.S.; Vasconcelos, A.G.; Carmo, F.F. \& Buchmann. F.S. 2015. Registro paleontológico em cavidade de formações ferríferas na Serra do Gandarela (MG). In: U. A. Ruchkys; L.E.P. Travassos; M.A. Rasteiro \& L.E. Faria (eds.) Patrimonio espeleológico em rochas ferruginosas: propostas para sua conservação no Quadrilátero Ferrifero, Minas Gerais, Sociedade Brasileira de Espeleologia, p. 238-249.

Bromley, R.G. 1990. Trace fossils: biology and taphonomy. London, Unwin Hyman, 280 p.

Buchmann, F.S.; Carmo, F.F.; Carmo, F.F.; Jacobi, C.M.; Ferreira, V.M.S. \& Frank, H.T. 2015. Paleotocas desenvolvidas em rochas ferruginosas: importante registro da megafauna no norte de Minas Gerais. In: F.F. Carmo \& L.H.Y. Kamino (eds.) Geossistemas Ferruginosos do Brasil: áreas prioritárias para conservação da diversidade geológica e biológica, patrimônio cultural e serviços ambientais, 3i Editora, p. 149-167.

Buchmann, F.S.; Lopes, R.P. \& Caron, F. 2009. Icnofósseis (Paleotocas e Crotovinas) atribuídos a mamíferos extintos no sudeste e sul do Brasil. Revista Brasileira de Paleontologia, 12:247-256. doi:10.4072/rbp.2009.3.07

Carmo, F.F.; Carmo, F.F.; Buchmann, F.S.C.; Frank, H.T. \& Jacobi, C.M. 2011a. Primeiros registros de paleotocas desenvolvidas em formações ferríferas, Minas Gerais, Brasil. In: CONGRESSO BRASILEIRO DE ESPELEOLOGIA, 31, 2011. Anais, Ponta Grossa, p. 531-540.

Carmo, F.F.; Carmo, F F.; Salgado, A.A.S. \& Jacobi, C.M. 2011 b. Novo sítio espeleológico em sistemas ferruginosos, no vale do rio Peixe Bravo, norte de Minas Gerais, Brasil. Espeleo-Tema 22:25-39.

Cartelle, C.; De Iuliis, G. \& Ferreira, L.R. 2009. Systematic revision of tropical brazilian Scelidotheriinae sloths (Xenarthra, Mylodontoidea). Journal of Vertebrate Paleontology, 29:555566. doi:10.1671/039.029.0231

Carvalho, I.S. \& Fernandes, A.C.S. 2000. Icnofósseis. In: I.S. Carvalho (ed.) Paleontologia, Editora Interciência, p. 95-118.

Dondas, A.; Isla, F.I. \& Carballido, J.L. 2009. Paleocaves exhumed from Miramar Formation (Ensenadense Stage-age, Pleistocene), Mar del Plata, Argentina. Quaternary International, 210:44-50. doi:10.1016/j.quaint.2009.07.001

De Muizon, C.; McDonald, H.G.; Salas, R. \& Urbina, M. 2004a. The Evolution of feeding adaptation of the aquatic sloth Thalassocnus. Journal of Vertebrate Paleontology, 24:398-410. doi: $10.1671 / 2429 b$

De Muizon, C.; McDonald, H.G.; Salas, R. \& Urbina, M. 2004b. The Youngest Species of the Aquatic Sloth Thalassocnus and a reassessment of the relationships of the Nothrothere Sloths (Mammalia: Xenarthra). Journal of Vertebrate Paleontology, 24:387-397. doi:10.1671/2429a

Edmond, G. 1985a. The fossil giant armadillos of North America (Pampatheriinae, Xenarthra = Edentata). In: G.G. Montgomery (ed.) The evolution and ecology of armadillos, sloths, and vermilinguas, Smithsonin Institution Press, p. 83-93.

Edmond, G. 1985b. The armor of fossil giant armadillos (Pampatheriinae, Xenarthra = Edentata). Austin, Texas Memorial Museum, University of Texas, 40 p. (Pearce-Sellards Series 40).

Fariña, R.A \& Vizcaíno, S.F. 1997. Allometry of the leg bones of some living and extinct armadillos (Dasypoda). Zeitschrift für Säugetierkunde, 62:65-70.

Frank, H.T.; Althaus, C.E.; Dario, E.M.; Tramontina, F.R.; Adriano, R.M.; Almeida, M.L.; Ferreira, G.F.; Nogueira, R. \& Breier, R. 2015. Underground chamber systems excavated by Cenozoic ground sloths in the state of Rio Grande do Sul, Brazil. Revista Brasileira de Paleontologia, 18:273-284. doi:10.4072/ rbp.2015.2.08

Frank, H.T.; Buchmann, F.C.S.; Lima, L.G.; Caron, F.; Lopes, R.P. \& Fornari, M. 2011. Karstic features generated from large palaeovertebrate tunnels in southern Brazil. Espeleo-Tema, 22:139-143.

Frank, H.T.; Buchmann, F.S.C.; Lima, L.G.; Fornari, M.; Caron, F. \& Lopes, R.P. 2012a. Cenozoic vertebrate tunnels in southern Brazil. In: R.G. Netto; N.B. Carmona \& F.M.W. Tognoli (eds.) 2012. Ichnology of Latin America - selected papers, Porto Alegre, Sociedade Brasileira de Palentologia, p. 141-157 (Monografias 2).

Frank, H.T. et al. 2012b. The complex history of a sandstone-hosted cave in the state of Santa Catarina, Brazil. Espeleo-Tema, 23:87-101.

Frank, H.T.; Lima, L.G.; Gerhard, N.P.; Caron, F.; Buchmann, F.S.C.; Fornari, M. \& Lopes, R.P. 2013. Description and interpretation of Cenozoic vertebrate ichnofossils in Rio Grande do Sul 
State, Brazil. Revista Brasileira de Paleontologia, 16:83-96. doi:10.4072/rbp.2013.1.07

Frey, R. 1975. The study of traces fossil. Berlim, Springer-Verlag, $562 \mathrm{p}$.

Frenguelli, J. 1921. Los terrenos de la costa atlântica em los alrededores de Miramar (Prov. de Buenos Aires) y sus correlaciones. Boletin de la Academia Nacional de Ciencias, 24:325-485.

Frenguelli, J. 1928. Observaciones geológicas em la region costanera sur de la Provincia de Buenos Aires. Anales de la Facultad de Ciencias de la Educacion, 2:1-694.

Kraglievich, J. 1952. El perfil geológico de Chapadmalal y Miramar, Prov. de Buenos Aires. Revista del Museo de Ciencias Naturales y Tradicionales, 1:8-37.

Lopes, R.P. \& Pereira, J.C. 2010. Fossils of Scelidotheriinae Ameghino, 1904 (Xenarthra, Pilosa) in the pleistocene deposits of Rio Grande do Sul, Brazil. Gaea, 6:44-52. doi:10.4013/ gaea.2010.61.05

Martins, M.S.; Karfunkel, J.; Noce, C.M.; Babinski, M.; PedrosaSoares, A.C.; Sial, A.N. \& Lyu, D. 2008. A sequência pré-glacial do Grupo Macaúbas na área-tipo e o registro da abertura do rifte Araçaí. Revista Brasileira de Geociências, 38:768-779.

McDonald, H.G. 2006. Sexual dimorphism in the skull of Harlan's ground sloth. Natural History Museum of Los Angeles County. Contributions in Science, 510:1-9.

McDonald, H.G. \& De Muizon, C. 2002. The cranial anatomy of Thalassocnus (Xenarthra, Mammalia), a derived Nothrothere from the Neogene of the Pisco Formation (Peru). Journal of Vertebrate Paleontology, 22:349-365. doi:10.1671/02724634(2002)022[0349:TCAOTX]2.0.CO;2

Naples, V.L. 1990. Morphological changes in the facial region and a model of dental growth and wear pattern development in Nothrotheriops shastensis. Journal of Vertebrate Paleontology, 10:372-389.

Noce, C. M.; Pedrosa-Soares, A.C.; Grossi-Sad, J.H.; Baars, F.J.; Guimarães, M.V.; Mourão, M.A.A.; Oliveira, M.J.R. \& Roque, N.C. 1997. Nova subdivisão estratigráfica regional do Grupo Macaúbas na Faixa Araçuaí: O Registro de uma bacia Neoproterozóica. Boletim do Núcleo Minas Gerais - Sociedade Brasileira de Geologia, 14:29-31.

Ogando, R.; Frank, H.T.; Buchmann, F.C.S.; Fornari, M.; Caron, F.; Lima, L.G. \& Lopes, R.P. 2011. Características cársticas generadas en terrenos graníticos a partir de túneles de paleovertebrados de la Megafauna de América del Sur. In: ENCUENTRO URUGUAYO DE ESPELEOLOGÍA, 3, 2011. Anais, Montevideo.

Ogando, R.; Frank, H.T.; Lima, L.G.; Caron, F.; Buchmann, F.C.S.; Fornari, M. \& Lopes, R.P. 2010. Paleocuevas en la región de la Formación Tacuarembó (Cuenca del Paraná), Uruguay. In: ENCUENTRO URUGUAYO DE ESPELEOLOGÍA, 2, 2010. Anais, Montevideo.

Paula-Couto, C. 1973. Edentados fósseis de São Paulo. Anais da Academia Brasileira de Ciências, 45:261-275.

Paula-Couto, C. 1980a. Um tatu gigante do Pleistoceno de Santa Catarina. Anais da Academia Brasileira de Ciências, 52:527-531.

Paula-Couto, C. 1980b. Propraopus punctatus (Lund, 1840) no Pleistoceno de Cerca Grande, Minas Gerais. Anais da Academia Brasileira de Ciências, 52:323-325.

Paula-Couto, C. 1982. Pleistocene armadillo from Cantagalo, State Rio de Janeiro. Iheringia, série geológica, 7:65-68.

Pedrosa-Soares, A.C.; Noce, C.M.; Alkmin, F.F.; Silva, L.C.; Babinski, M.; Cordani, U. \& Castaneda, C. 2007. Orógeno
Araçaí: Síntese do conhecimento 30 anos após Almeida 1977. Geonomos, 15:1-16.

Pedrosa-Soares, A.C.; Noce, C.M.; Vidal, P.H.; Monteiro, R.L.B.P. \& Leonardos, O.H. 1992. Towards a new tectonic model for the Late Proterozoic Araçaí (SE-Brazil) West Mongolian (SW African) belt. Journal of South American Earth Sciences, 6:3347. doi:10.1016/0895-9811(92)90015-Q

Quintana, C.A. 1992. Estructura interna de una paleocueva, posiblemente de un Dasypodidae (Mammalia, Edentata) del Pleistoceno de Mar del Plata (provincia de Buenos Aires, Argentina). Ameghiniana, 29:87-91.

Ruchkys, U.A.; Bittencourt, J.S. \& Buchmann, F.S.C. 2014. A paleotoca da Serra do Gandarela e seu potencial como geossítio do Geoparque Quadrilátero Ferrífero, Minas Gerais. Caderno de Geografia, 24:249-263. doi:10.5752/P.23182962.2014v24n42p249

Ruchkys, U.A.; Travassos, L.E.P.; Rasteiro, M.A. \& Faria, L.E. 2015. Patrimonio espeleológico em rochas ferruginosas: propostas para sua conservação no Quadrilátero Ferrífero, Minas Gerais. $1^{\mathrm{a}}$ ed. Campinas, Sociedade Brasileira de Espeleologia, 354p.

Seilacher, A. 1953. Studien zur paläontologie: 1. Über die methoden der palichnologie. Neues Jahrbuch für Geologie und Paläontologie, Abhandlungen, 96:421-452.

Uhlein, A.; Trompete, R.R. \& Egydio-Silva, M. 1998. Proterozoic rifting and closure, SE border of the São Francisco Craton, Brazil. Journal of South American Earth Sciences, 11:191-203. doi:10.1016/S0895-9811(98)00010-8

Uhlein, A.; Trompette, R.R.; Egydio-Silva, M. \& Vauchez, A. 2007. A glaciação Sturtiana (750 MA), a Estrutura do rifte Macaúbas-Santo Onofre e a estratigrafia do Grupo Macaúbas, Faixa Araçuaí. Geonomos, 15:45-60.

Vilela, F.T. 2010. Caracterização de metadiamictitos ferruginosos da Formação Nova Aurora (Grupo Macaúbas, Orógeno Araçuaí) a oeste de Salinas, MG. Programa de Pós-Graduação em Geologia, Universidade Federal de Minas Gerais, Dissertação de Mestrado, $135 \mathrm{p}$.

Vilela, O.V. 1986. As jazidas de minério de ferro dos municípios de Porteirinha, Rio Pardo de Minas, Riacho dos Machados e Grão-Mogol, norte de Minas Gerais. In: C. Schobbenhaus \& C.E.S. Coelho (eds.) Principais depósitos minerais do Brasil: Ferro e metais da indústria do aço, v.2, DNPM/ CVRD, p. 111-120.

Vilela, O.V.; Pena, C.A.; Barsotti, T.M. \& Jorge, A.S. 1978. Prospecção das jazidas de minério de ferro dos municípios de Porteirinha, Rio Pardo de Minas, Riacho dos Machados e GrãoMogol, norte de Minas Gerais. In: CONGRESSO BRASILEIRO DE GEOLOGIA, 20, 1978. Anais, Recife, p. 1914-1921.

Viveiros, J.F.M.; Sá, E.L.; Vilela, O.V.; Santos, O.M. \& Moreira, J.M.P. 1979. Geologia dos vales dos Rios Peixe Bravo e Alto Vacaria. Norte de Minas Gerais. In: SIMPÓSIO GEOLOGIA DE MINAS GERAIS, 1, 1979. Boletim, Diamantina, p. 75-87.

Vizcaíno, S.F.; Fariña; R.A. \& Mazzeta, G. 1999. Ulnar dimensions and fossoriability in armadillos and other South American mammals. Acta Theriologica, 44:309-320.

Vizcaíno, S.F.; Milne, N. \& Bargo, M.S. 2003. Limb reconstruction of Eutatus seguini (Mammalia: Xenarthra: Dasypodidae). Paleobiological implications. Ameghiniana, 40:89-101.

Vizcaíno, S.F.; Zárate, M.; Bargo, M.S. \& Dondas, A. 2001. Pleistocene burrows in the Mar del Plata area (Argentina) and their probable builders. Acta Palaeontologica Polonica, 46:157-169. 
Zárate, M.A.; Bargo, M.S.; Vizcaíno, S.F.; Dondas, A. \& Scaglia, O. 1998. Estructuras biogénicas en el Cenozoico tardío de Mar del Plata (Argentina) atribuibles a grandes mamíferos. Revista de la Asociacion Argentina de Sedimentología, 5:95-103.

Zárate, M.A. \& Fasano, J.L. 1989. The Plio-Pleistocene record of the central eastern Pampas, Buenos Aires province, Argentina: the
Chapadmalal case study. Palaeogeography, Palaeoclimatology, Palaeoecology, 72:27-52. doi:10.1016/0031-0182(89)90130-2

Received in May, 2015; accepted in August, 2016. 